\title{
Uso das técnicas de geoprocessamento no mapeamento dos focos de incêndio na microrregião da Serra do Teixeira/PB no período de
}

\section{4-2019}

As queimadas tem sido uma ameaça recorrente a biodiversidade em diversas regiões do mundo. Nas regiões semiáridas a utilização habitual do fogo como alternativa mais pratica e barata nas atividades agropecuárias tem se tornado um fator de risco quando não é feito o controle da extensão dessas queimadas, prejudicando os elementos da paisagem e fatores como a fertilidade do solo. O objetivo deste estudo foi demonstrar como as técnicas de geoprocessamento são eficientes na análise dos focos de incêndio em uma dada região. A coleta de dados no Portal do Monitoramento de Queimadas e Incêndios do Instituto Nacional de Pesquisas Espaciais (INPE), permitiu a espacialização das informações e a determinação do raio de influência das amostras ao longo da microrregião da Serra do Teixeira/PB, no período de 2014 a 2019. Os resultados demonstram, uma análise satisfatória dos focos de incêndio identificados via satélite por meio do uso de técnicas de geoprocessamento e a relação direta de elementos topográficos e meteorológicos nas ações de prevenção e combate desses eventos. Desta forma, as geotecnologias se mostram ferramentas eficientes no monitoramento periódico das queimadas e na criação de um banco de dados que sirva como subsidio no planejamento e gestão territorial de áreas suscetíveis a determinados eventos adversos que tendem a gerar prejuízos socioeconômicos.

\section{Use of geoprocessing techniques in the mapping of fire spots in the micro region of Serra da Teixeira/PB in the period 2014-2019}

\begin{abstract}
Fires have been a threat to biodiversity in different regions of the world. In semi-arid regions, the usual use of fire is a more practical and inexpensive alternative in agricultural activities that cause a risk when the extent of this damage is not controlled, damaging elements of the landscape and factors such as soil fertility. The aim of this study was to demonstrate the efficiency of geoprocessing techniques in the analysis of fire outbreaks in a specific region. The data collection on the Burns and Fires Monitoring Portal of the National Institute for Space Research (INPE) allowed the spatialization of information and the determination of the radius of influence of the pieces along the micro region of Serra da Teixeira/PB, in the period of 2014 to 2019. The results demonstrate a satisfactory analysis of the fire outbreaks caused by the satellite through the use of geoprocessing techniques and the direct relationship of topographic and meteorological elements in the actions to prevent and combat these events. In this way, as geotechnologies, efficient tools are shown in the periodic monitoring of fires and in the creation of a database that serve as a subsidy for planning and territorial management of areas susceptible to adverse events that are reproduced socioeconomic.
\end{abstract}

Keywords: Geoprocessing; Burned; Heat maps.

Topic: Tecnologia, Modelagem e Geoprocessamento

Reviewed anonymously in the process of blind peer.
Received: 19/03/2020

Approved: $22 / 04 / 2020$
Priscilla Gomes Barbosa (iD

Universidade Estadual da Paraíba, Brasil http://lattes.cnpq.br/4823633249815596 http://orcid.org/0000-0002-3054-5680 priscillagomes.engambiental@gmail.com

\section{José Fideles Filho}

Universidade Estadual da Paraíba, Brasil

http://lattes.cnpq.br/1994594710013360 fidelesfilho@uol.com.br

\section{Olávio Rocha Neto (iD)}

Universidade Estadual da Paraíba, Brasil http://lattes.cnpq.br/9750143696204633 http://orcid.org/0000-0003-0152-5397 olavorochaneto12@gmail.com

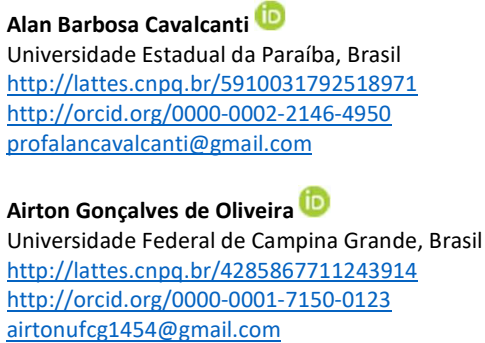

Referencing this:

BARBOSA, P. G.; FIDELES FILHO, J.; ROCHA NETO, O.; CAVALCANTI, A. B.; OLIVEIRA, A. G.. Uso das técnicas de geoprocessamento no mapeamento dos focos de incêndio na microrregião da Serra do Teixeira/PB no período de 2014-2019. Revista Ibero Americana de Ciências Ambientais, v.11, n.3, p.485-493, 2020. DOI: http://doi.org/10.6008/CBPC2179-6858.2020.003.0037 


\section{INTRODUÇÃO}

Os incêndios, fatores de perturbação que influenciam ecossistemas florestais, apresentam forte impacto sobre as condições bióticas e abióticas. Considerando a ocorrência como um elemento de perturbação natural, é um componente essencial para o funcionamento de muitos ecossistemas, no entanto, o aumento significativo das ocorrências devido as atividades antrópicas tem gerando grande preocupação. Uma vez que, resulta em um desequilíbrio entre os elementos do meio, o que leva a fragmentação da paisagem e sua degradação (ADÁMEK et al., 2015), podendo se expandir livremente pela mata, consumindo seus mais variáveis tipos de combustíveis e podendo atingindo inclusive centros urbanos (SANTOS et al., 2015).

Os incêndios florestais geram transtornos locais, regionais e globais, a depender do seu potencial grau de abrangência. Do ponto de vista local, causam a degradação da flora, impactos sobre a biodiversidade e consequentemente impactos econômicos. Em escala regional, a fumaça provoca problemas para a saúde humana e animal, além de afetar os meios de transporte, pois tende a diminuir a visibilidade. Do ponto de vista global, promovem aumento nas emissões de carbono para a atmosfera, podendo ter consequências para o clima planetário (HERAWATI et al., 2011).

Na região semiárida, é prática cultural das populações a remoção da vegetação utilizando métodos tradicionais de desmatamento e queima, o que tem inviabilizado o uso do solo aos longos dos anos, uma vez que esse procedimento acarreta a redução drástica da fertilidade e da produção. Devido aos grandes impactos que as queimadas descontroladas causam em uma dada localidade, o monitoramento e a geração de informações que auxiliem no planejamento e gestão de possíveis eventos dessa natureza são de extrema importância para os diversos setores da sociedade civil.

Fernandes et al. (2011) tem destacado como a utilização de técnicas de geoprocessamento podem facilitar a analise temporal e espacial dos focos de incêndio em uma dada região, possibilitando uma visão holística da dinâmica do risco, bem como, auxiliar na estratégia de combate e prevenção. Neste sentido, Vijayakumar et al. (2015) descrevem a importância de um banco de dados consistente de registros históricos e mapas de ocorrência de incêndios com o objetivo de proporcionar uma melhor perspectiva sobre as mudanças reais no comportamento dos focos de incêndio para compreender melhor a relação entre fogo e clima.

Portanto, propõe-se a análise dos focos de calor na microrregião da Serra do Teixeira/PB, através do uso de técnicas de geoprocessamento, utilizando dados do período de 2014 à 2019 obtidos no Portal do Monitoramento de Queimadas e Incêndios do Instituto Nacional de Pesquisas Espaciais (INPE), com o objetivo de mapear todas as ocorrências de focos de incêndio identificadas por satélites, visando espacializar essas informações de forma holística possibilitando nortear a tomada de decisão em relação a queima descontrolada da vegetação na região de estudo. 


\section{METODOLOGIA}

A microrregião da Serra do Teixeira/PB abriga 11 municípios e se localiza ao sul do estado da Paraíba (Figura 1), é uma região tipicamente serrana que abriga elementos florísticos da caatinga e mata atlântica, bem como grandes formações rochosas que contribuem para o comportamento climático, ambiental, social e econômico da região.

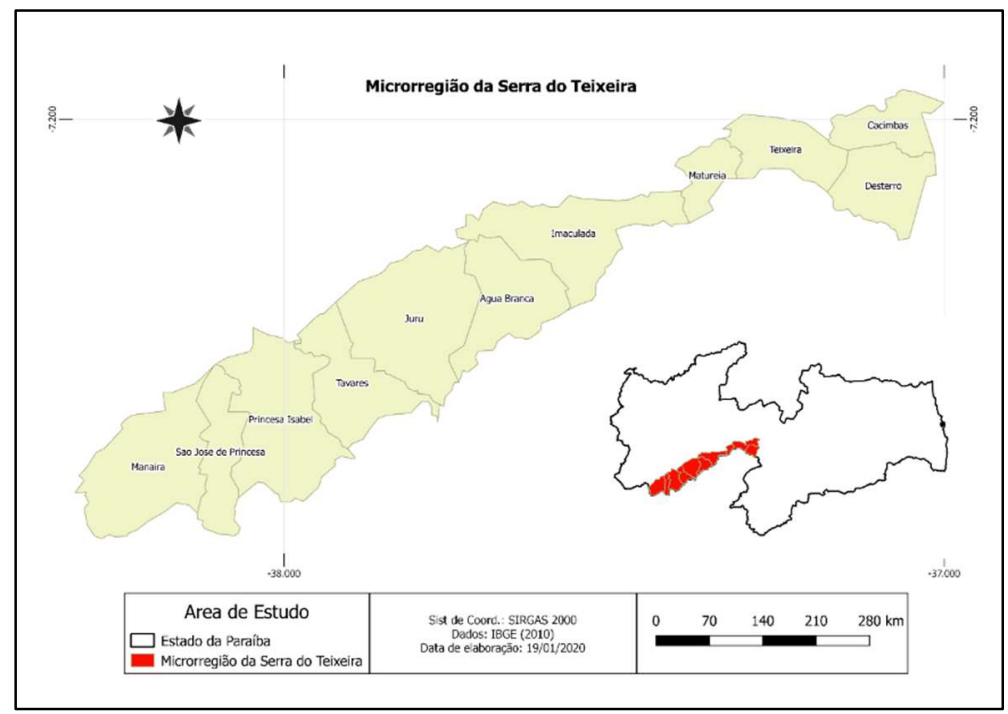

Figura1: Microrregião da Serra do Teixeira/PB.

A espacialização dos focos de incêndio dos últimos 6 anos envolveu a utilização dos seguintes materiais: arquivo shapefiile com a delimitação da área de estudo, dados de focos de calor (2014-2019), dados pluviométricos (2014-2019) e MDE (Modelo digital de Elevação). A base com a delimitação da microrregião serviu como chave de interpretação dos dados analisados. Os dados de focos de calor utilizados foram encontrados no portal de queimadas do INPE, são dados coletados por detecção via satélite de radiância emitida por materiais em chamas, os quais emitem energia principalmente na faixa termal média de 3,7 a 4,1 $\mu \mathrm{m}$ do espectro óptico.

O banco de dados envolve informações como: localização do incêndio, horário de ocorrência, elementos do terreno (relevo, altitude), dados pluviométricos no dia da ocorrência, entre outras informações, permitindo uma discussão consistente acerca dos focos identificados. Os dados foram todos manipulados em ambiente SIG (Sistema de Informação Geográfica) através do software Qgis 2.18 e envolveu a espacialização dos dados importados em arquivo do tipo shapefile através de índices e algoritmos capazes de determinar o raio de influência de cada foco de calor identificado, com Sistema de Referência de Coordenadas definido em SIRGAS 2000/UTM24S.

$O$ arquivo MDE utilizado para análise do terreno, possui uma resolução espacial de $30 \mathrm{~m}$, com dados do tipo matricial, que representam os elementos topográficos da superfície terrestre, para este estudo foram extraídas informações relativas a declividade e hipsometria, consideradas como sendo características que contribuem para a frequência, velocidade de propagação e tamanho das áreas atingidas por queimadas.

Os dados referentes a precipitação anual média da área de estudo entre os anos de 2014 e 2019, foram caracterizados a partir de informações coletadas junto ao banco de dados da AESA (Agência Executiva 
de Gestão das Águas do Estado da Paraíba) e envolveu a interpolação dos postos pluviométricos de cada município que compõe a microrregião da Serra do Teixeira e a posterior espacialização dos dados através do método das isoietas disponível no software Qgis.

\section{RESULTADOS E DISCUSSÃO}

A análise do comportamento das atividades antrópicas em uma dada região é um instrumento muito importante para o entendimento dos potenciais fenômenos que podem vir a gerar prejuízos socioeconômicos e ambientais. White et al. (2011) evidenciam a influência de variáveis meteorológicas como um dos principais fatores de risco para ocorrência e consequente redução dos focos de incêndio, a depender diretamente da água precipitada. Outro fator preponderante neste tipo de análise é o comportamento topográfico da área que influencia diretamente na identificação e no combate das queimadas.

Os levantamentos dos dados topográficos são primordiais quando se considera a necessidade de planejamento territorial para a manutenção da dinâmica ambiental, uma vez que, possibilitam a compreensão de diversos fenômenos de ordem estrutural como: declividade, erodibilidade, entre outros (CHAVES et al., 2013). Os modelos digitais de elevação (MDE) são importantes fontes de informação em países como o Brasil, pois mesmo com a grande quantidade de informações produzidas sobre o relevo, estas não possuem o detalhamento necessário em algumas regiões e é praticamente inexistente em outras.

A partir da utilização dos Sistemas de Informações Geográficas, a obtenção dos atributos do relevo passou a ser um procedimento de fácil acesso, uma vez que existem banco de dados geoespaciais de órgãos oficiais que permitem a extração dessas informações através de softwares gratuitos. A parametrização da morfologia do relevo por meio de SIG envolve o processo de extração de atributos quantitativos da topografia, e a posterior espacialização das informações em mapas temáticos que possibilitam a visualização ao longo de todo o território. As definições dos elementos de relevo são fatores capazes de possibilitar um zoneamento fisiográfico, que possibilita entre outras ações a distribuição adequada da população e das atividades econômicas, de modo a gerar um menor grau de impacto sobre o território, uma vez que, quanto maior a declividade de uma área maior tende a ser o potencial degradante que as atividades antrópicas exercem sobre a dinâmica local, visto o alto grau de vulnerabilidade que essas áreas possuem.

A análise hipsometrica e da declividade da microrregião da Serra do Teixeira (Figura 2) demonstra uma região com características topográficas íngremes, o que sugere segundo vários autores, uma região suscetível a queimadas. Os conhecimentos desses fatores podem auxiliar na prevenção e no combate de focos de incêndio em áreas de difícil acesso, uma vez que possibilita informações holísticas de todo o espaço envolvido.

Outro fator chave nesse tipo de estudo é o índice pluviométrico, que pode indicar a tendência que determinada área tem de sofrer queimadas naturais, devido à fatores como: baixa umidade do ar, descargas elétricas (raios), entre outros. A microrregião da Serra do Teixeira, se encontra dentro da região semiárida, onde o índice pluviométrico médio se encontra na faixa de $200-800 \mathrm{~mm}$ anuais (Figura 3), com $70 \%$ das chuvas concentradas nos primeiros cinco meses do ano, associadas a uma distribuição irregular, o que tende a gerar 
um cenário de escassez hídrica e instabilidade da dinâmica ambiental, tornando-a suscetível a eventos de cunho natural e/ou antrópico que causam queimadas e a consequente degradação ambiental.

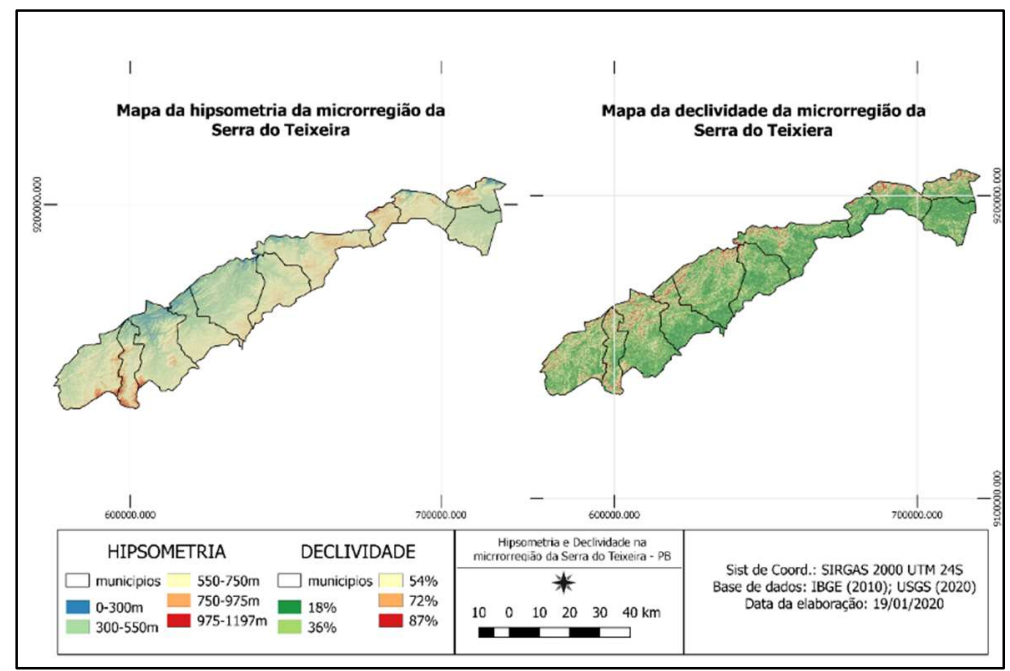

Figura 2: Mapa de declividade e hipsométrico da microrregião da Serra do Teixeira/PB.

De modo geral, o período analisado se caracterizou como seco, com chuvas irregulares e espaçadas durante o ano, o que agrava ainda mais a dinâmica de convivência com o semiárido. A baixa taxa de precipitação é um importante quesito a ser analisado neste tipo de estudo, visto que, atua como facilitador das queimadas, uma vez que altera a umidade do ar tornando a vegetação suscetível a eventos naturais e/ou antrópicos causadores. Por outro lado, a alta taxa de precipitação é um importante fator no processo de diminuição dos focos de incêndio, uma vez que atua diretamente no foco a ser combatido, além de contribuir para o aumento da taxa de umidade do ar.

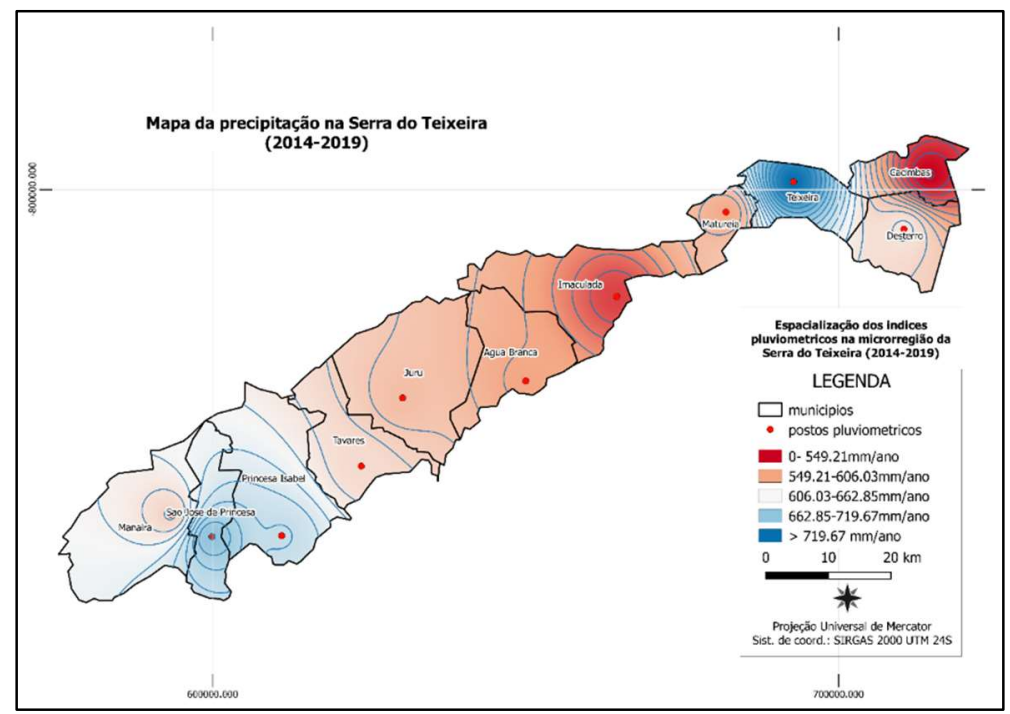

Figura 3: Mapa de precipitação da microrregião da Serra do Teixeira/PB (2014-2019).

A microrregião da Serra do Teixeira preserva características primarias de ocupação, inclusive no setor agrícola, onde o fogo é bastante utilizado na limpeza e abertura de áreas de cultivo, devido a principalmente ao seu baixo e custo e fácil operação. Neste sentindo, as queimadas se agravam nos longos períodos de seca da região, quando a umidade da vegetação é baixa, e o seu combate é dificultado pelos obstáculos geográficos (COUTINHO et al., 2016). 
Neste estudo, a análise dos focos de incêndio incluiu um período de 2.191 dias e envolveu os anos de: 2014, 2015, 2016, 2017, 2018 e 2019. A coleta das informações relativas as ocorrências de focos de incêndio foram realizadas no Portal de Monitoramento de Queimadas e Incêndios do Instituto Nacional de Pesquisas Espaciais (INPE), onde por meio de download de arquivos shapefile de cada ano, foi possível espacializar os focos de queimadas identificados por satélites em ambiente SIG (Sistema de Informações Geográficas) e gerar uma visão geral das ocorrências na microrregião da Serra do Teixeira/PB (Figura 4). Vale ressaltar que, em virtude das características regionais, quanto maior a quantidade de focos identificados maior serão os prejuízos ambientais, uma vez que, a depender da extensão e da duração das queimadas os elementos locais da paisagem não conseguem se recuperar devido ao potencial do impacto sofrido, gerando um cenário suscetível a processos de desertificação e outros fatores que impedem a continuidade de atividades econômicas na região.

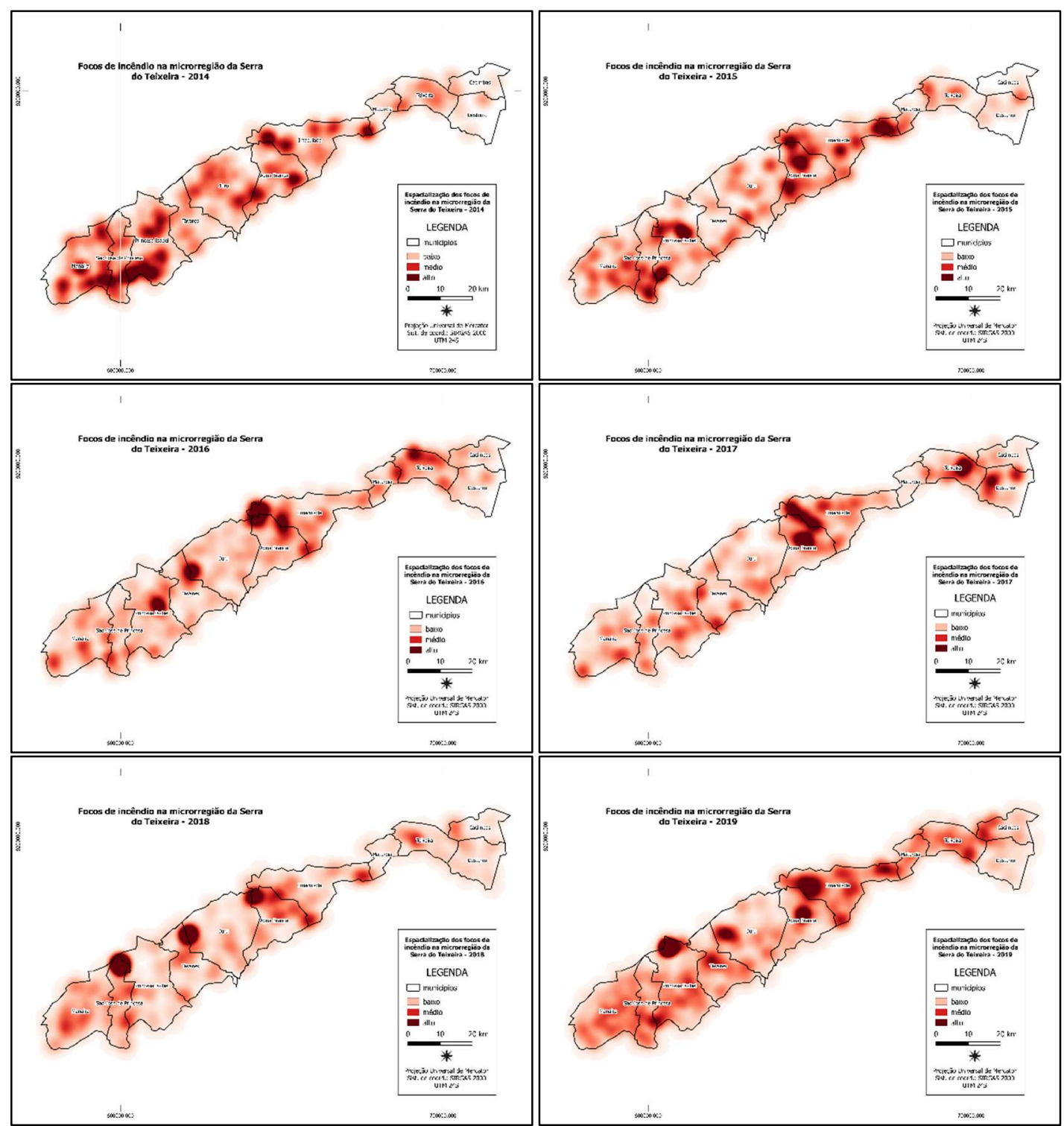

Figura 4: Mapa da espacialização dos focos de incêndio na microrregião da Serra do Teixeira no período 2014-2019.

Os mapas de calor gerados a partir dos focos de incêndio identificados, obedecem ao contexto do método estatístico da estimativa de curvas de densidade, onde, a partir de cada observação feita é ponderada uma distância de influência em relação a um valor central, o núcleo. As informações foram 
plotadas, através do método da interpolação, que considera o foco da intensidade pontual de um determinado fenômeno estudado. Estudos desse tipo, são capazes de auxiliar uma análise visual mais consistente diante da excessiva concentração de focos de incêndio em pontos específicos, outro fator importante é fazer com que a representação não fique limitada as áreas pré-definidas, como é o caso dos polígonos municipais, permitindo uma análise holística do raio de abrangência do foco de calor (SOUZA et al., 2013; VIERIA et al., 2018).

Na Figura 4 observa-se que os anos de 2014, 2015 e 2019 foram os que tiveram o maior número de focos de incêndio, nos demais anos visualiza-se ocorrências mais espaçadas ao logo do território. O Gráfico 1 monstra o quantitativo de focos ao logo do período analisado em cada um dos municípios que compõe a microrregião da Serra do Teixeira, o levantamento numérico apresenta que o maior número de focos ocorreu entre os anos de 2014, 2015, 2016 e 2017 com uma posterior redução nos anos de 2018 e 2019. Esta discrepância se dá principalmente pela distribuição e extensão dos focos ao longo da região, quanto mais próximas as amostras maiores o raio de influência e quanto mais distantes as amostras menores o raio de influência, fazendo com que a visualização das informações possa sofre distorções em relação aos reais valores quantitativos, no entanto, do ponto de vista da analise espacial esse quesito pode ser atribuído a fatores como: interpretação do operador e técnicas de análise utilizadas.

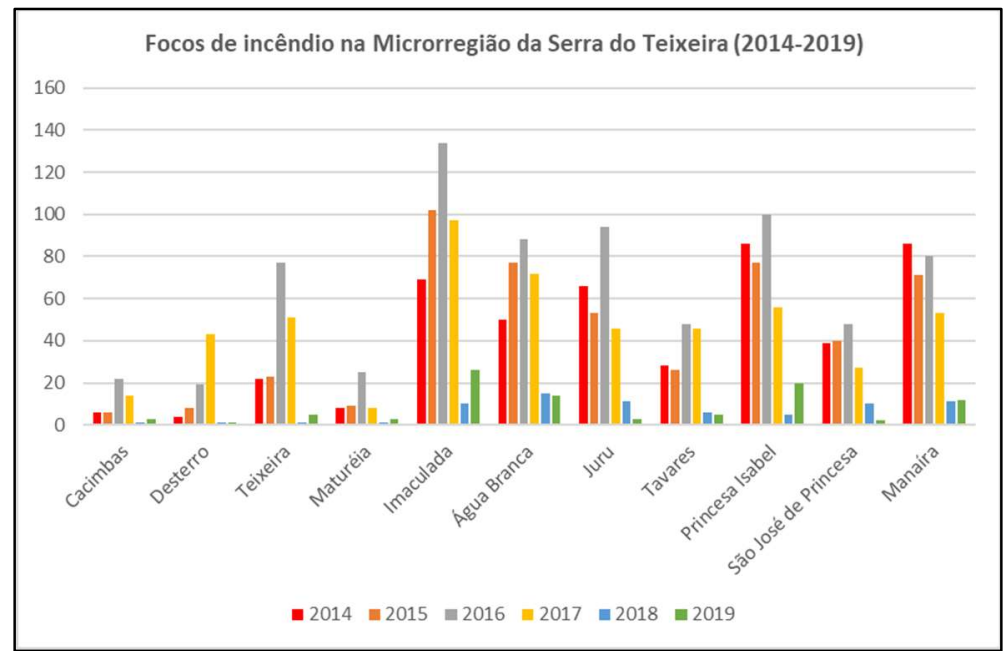

Gráfico 1: Quantitativo dos focos de incêndio na Microrregião da Serra do Teixeira 2014-2019.

Um dos pontos negativos da obtenção desse tipo de informação por satélite, são as interferências atmosféricas que os sensores sofrem, no entanto, esses erros podem ser corrigidos através dos pós processamento desses dados, etapa onde ocorre a redução dessas interferências (COUTINHO et al., 2016). Outras limitações na detecção de fogo em vegetação via satélite, são: as limitações técnicas para identificação de queimadas de pequeno porte, uma vez que o satélite não consegue identificar focos em uma linha de frente com largura inferior a 50m, devido a resolução multiespectral das imagens de satélite que operam em uma faixa de pixel que varia de $82-30 \mathrm{~m}$. A resolução temporal do satélite, em algumas situações o fogo pode iniciar e terminar durante o intervalo de passagem do satélite. Fogo em regiões íngremes é outro fator a ser analisado, visto que a orbita do satélite não tem acesso a ambos nos lados de uma montanha. Fatores como fogo superficial em mata fechada e demais situações restringem a eficiência desta técnica 
(INPE, 2016; BARLOW et al., 2012).

De modo geral, a espacialização dos focos de incêndio através de ferramentas de geoprocessamento e sensoriamento remoto, tem sido um grande avanço na identificação das ocorrências em áreas de difícil acesso. A disponibilização periódica dos dados por parte do INPE, possibilita a criação de um banco de dados consistente de informações que podem servir de auxílio nos estudos de assuntos dessa natureza, bem como para o entendimento comportamental da região e os impactos socioambientais gerados pelas queimadas.

Sabendo que as queimadas são elementos de causa antrópica ou natural a depender da sua ignição, as populações locais interferem nos ciclos anuais do fogo em muitas partes do mundo, diminuindo ou aumentando as épocas e áreas mais propicias a ocorrência do fogo (BEDIA et al., 2015), a utilização de técnicas de sensoriamento remoto e geoprocessamento são ferramentas eficientes no auxílio do monitoramento desse fenômeno. Nesse sentido, Linn et al. (2012) coloca a importância do entendimento do comportamento do fogo como sendo um fator fundamental nas respostas diante das condições ambientais, no sentido de antecipar situações graves ou impactos de grande magnitude, além de auxiliar na melhoria das decisões sobre a gestão de incêndios florestais.

Portanto, estudos desta natureza, considerando as diversidades regionais intrínsecas de cada localidade e associando técnicas remotas de analise são capazes de criar bancos de dados eficientes para gestores, de modo a permitir o desenvolvimento de ações de planejamento integrado que minimizem os efeitos das queimadas que atingem grandes áreas e que tendem a alterar a dinâmica socioambiental.

\section{CONCLUSÕES}

De acordo com o que foi discutido, as geotecnologias são ferramentas importantes na espacialização e visão holística dos focos de incêndio em uma região, permitindo o conhecimento das áreas com maiores ocorrências e possibilitando o direcionamento de ações de planejamento e gestão com o intuito de mitigar os impactos causados pelas queimadas.

Na microrregião da Serra do Teixeira/PB, observou-se uma maior ocorrência dos focos próximo as áreas urbanas e em setores com maior grau de inclinação, no entanto, nos 6 anos analisados houve um crescimento entre os anos de 2014 e 2017 e uma tendência de redução dos focos entre os anos de 2018 e 2019 segundo as amostras identificadas via satélite.

\section{REFERÊNCIAS}

ADÁMEK, M.; BOBEK, P.; HADINCOVÁ, V.; WILD, J.; KOPECKY, M.. Forest fires within a temperate landscape: a decadal and millennial perspective from a sandstone region in Central Europe. Forest Ecology and Management, v.336, n.2015, p.81-90, 2015.

BARLOW, J.; PARRY, L.; GARDNER, T. A.; FERREIRA, J. N.. The critical importance of considering fire in REDD+ programs. Biological Conservation, v.154, p.1-8, 2012. DOI: http://dx.doi.org/10.1016/j.biocon.2012.03.034

BEDIA, J.; GARCÍA, S. H.; GUTIÉRREZ, J. M.; MORENO, J. M. Global patterns in the sensitivity of burned área to fire- wearher: implications for climate change. Agricultural and Forest Meteorology, v.214, n.2015, p.369-379, 2015. DOI: http://dx.doi.org/10.1016/j.agrformet.2015.09.002

COUTINHO, M. A. N.; FERNANDES, A. C. G.; SANTOS, V. G.; NASCIMENTO, C. R.. Análise comparativa dos índices de vegetação NDVI, SAVI, RATIO E IAF para identificação de queimadas. Caderno de Ciências Agrárias, Belo Horizonte, v.8, n.1, p.70-81, 2016.

CHAVES, M. E. D.; LOURENÇONI, D.; SOARES, J. F.; FERREIRA, E.; PENA, M. R. S.; MIRANDA, L. H.. Geomorfologia e Planejamento Ambiental: Mapeamento do Relevo e 
Delimitação das Classes de Declividade no Município de Campos Gerais/MG. In: CONGRESSO NACIONAL DE MEIO AMBIENTE, 10. Anais. Poços de Caldas, 2013. p.1-6.

FERNANDES, M. C.; COURA, P. H. F.; SOUSA, G. M.; AVELAR, A. S.. Avaliação geoecológica de susceptibilidade à ocorrência de incêndios no estado do Rio de Janeiro, Brasil. Floresta e Ambiente, v.18, n.3. p.299-309, 2011. DOI: http://dx.doi.org/10.4322/floram.2011.050

HERAWATI, H.; SANTOSO, H.. Tropical forest susceptibility to and risk off ire under changing climate: a review off ire nature, policy and institutions in Indonesia. Forest Policy and Economics, v.13, n.2011, p.227-233, 2011. DOI: http://dx.doi.org/10.1016/i.forpol.2011.02.006

INPE. Instituto Nacional de Pesquisas Espaciais. Banco de Dados do Programa de Monitoramento de Queimadas e Incêndios. INPE, 2016.

LINN, R. R.; CANFIELD, J. M.; CUNNINGHAM, P.; EDMINSTER, C.; DUPUY, J. L.; PIMONT, F.. Using periodic line fires to gain a new perspective on multi-dimensional aspects of forward fire spread. Agricultural and Forest Meteorology, v.157, n.2012, p.60-76, 2012. DOI: http://dx.doi.org/10.1016/j.agrformet.2012.01.014

SANTOS, W. S.; SOUTO, P. C.; SOUTO, J. S.; MENDONÇA, I. F. C.; SOUTO, L. S.; MARACAJÁ, P. B.. Estimativa dos riscos de ocorrência de incêndios florestais do Parque Estadual Pico do Jabre, na Paraíba. Agropecuária Cientifica do Semiárido, Patos, v.11, n.1, p.80-84, 2015

SOUZA, N. P.; SILVA, E. M. G. C.; TEIXEIRA, M. D.; LEITE, L. R.; REIS, A. A.; SOUZA, L. N.; JUNIOR, F. W. A.; RESENDE, T. A. Aplicação do estimador de densidade kernel em unidades de conservação na bacia do rio São Francisco para análise de focos de desmatamento e focos de calor. In: SIMPOSIO BRASILEIRO DE SENSORIAMENTO REMOTO, 16. Anais. São José dos Campos: INPE, 2013.

VIEIRA, M. H. P.; PEREIRA, E. F.; VIEIRA, J.; LOUZADA, R. O.; SILVA, M. C. A.; FERREIRA, L. M.. Mapas de Kernel como Alternativa ao Monitoramento Ambiental: Análise das indústrias que realizam emissões nos municípios do estado de Mato Grosso do Sul, nos anos 2008 e 2018. In: SIMPÓSIO DE GEOTECNOLOGIAS NO PANTANAL, 7. Anais. Jardins, 2018. p.627-636.

VIJAYAKUMAR, D. B. I. P.; RAULIER, F.; BERNIER, P.; GAUTHIER, S.; BERGERON, Y.; POTHIER, D.. Lenghening the historical records off ire history over large áreas of boral forest in eastern Canada using empirical relationships. Forest Ecology and Management, v.347, p.30-39, 2016. DOI: http://dx.doi.org/10.1016/j.foreco.2015.03.011

WHITE, B. L. A.; RIBEIRO, A. S.. Análise da precipitação e sua influência na ocorrência de incêndios florestais no Parque Nacional Serra de Itabaiana, Sergipe, Brasil. Ambi-Água, Taubaté, v.6, n.1, p.148-156, 2011.

A CBPC - Companhia Brasileira de Produção Científica (CNPJ: 11.221.422/0001-03) detém os direitos materiais desta publicação. Os direitos referem-se à publicação do trabalho em qualquer parte do mundo, incluindo os direitos às renovações, expansões e disseminações da contribuição, bem como outros direitos subsidiários. Todos os trabalhos publicados eletronicamente poderão posteriormente ser publicados em coletâneas impressas sob coordenação da Sustenere Publishing, da Companhia Brasileira de Produção Científica e seus parceiros autorizados. Os (as) autores (as) preservam os direitos autorais, mas não têm permissão para a publicação da contribuição em outro meio, impresso ou digital, em português ou em tradução. 